\title{
Formar-se com Arte entre Museu e Pré-escola
}

\author{
Franca Zuccoli' \\ 'Universitá Degli Studi Milano Bicocca, Milão - Itália
}

RESUMO - Formar-se com Arte entre Museu e Pré-escola. O percurso que uma educação à arte permite desenvolver, dentro da Pré-escola e dentro do museu, com crianças de 3 a 6 anos, é uma forma diferente de se posicionar em relação às potencialidades das crianças e dos/as professores/as. Neste artigo deseja-se apresentar a importância da formação de professores/as realizada nos museus, onde o contato com as obras presentes é elemento de desenvolvimento da profissionalidade. A concepção da criação artística se caracteriza, de fato, por implicar escolhas, reflexões, tentativas, mudanças, atingindo uma produção visível e compartilhada. Estas mesmas ações podem ser realizadas, após a experiência no museu, se o próprio museu se oferece como estímulo para novas hipóteses.

Palavras-chave: Formação. Crianças Pequenas. Pré-escola. Práticas Pedagógicas. Museu.

ABSTRACT - Teacher Training between the Museum and the Early Childhood Education. Art education in early childhood education schools and at museums with children aged 3 to 6 is a different way to relate to the potential of children and educators. In this paper we emphasize the importance of the teacher training carried out at museums, where contact with artwork is an element in skills development. The concept of artistic creation is characterized by implications of choices, thoughts, attempts and changes leading to a visible and shared production. These same actions can be carried out, after the experience at the museum, if the museum itself is offered as a stimulus for new hypotheses.

Keywords: Education. Young Children. Early Childhood Education. Teaching Practices. Museum.

Educação \& Realidade, Porto Alegre, v. 40, n. 4, p. 1045-1060, out./dez. 2015.1045 http://dx.doi.org/10.1590/2175-623651713 


\title{
Introdução
}

Muito frequentemente, quase cotidianamente, dentro das creches e das pré-escolas se praticam atividades artísticas e expressivas com as crianças. Dedicar muita atenção a este aspecto é uma peculiaridade que caracteriza estas estruturas educativas. Pode-se subdividir esta atenção principalmente em duas vertentes: primeiro a organização dos espaços, decorados cuidadosamente seguindo uma proposta estética compartilhada pelos adultos, observando as cores, a mobília, e inserindo como elemento de decoração as próprias obras das crianças; em segundo lugar a organização das atividades que propõem a manipulação de materiais maleáveis ou a pintura, o desenho ou a colagem, experimentos com o corpo e instalações espaciais, dentro do âmbito da educação artística ou educação à imagem, como também é chamada. Também nos mesmos programas ou diretrizes nacionais, por exemplo, no caso daquelas italianas de 2012, para as pré-escolas a atenção dedicada a esta área do saber é extremamente sentida e destacada como um dos aspectos a ser considerado e a se desenvolver seja na planificação das turmas, seja na presença das crianças. Isto, nas diretrizes nacionais italianas se pode evidenciar a partir das seguintes afirmações, que se referem ao que na Itália são definidos campos de experiência, neste caso intitulado Imagens, sons, cores, aqui reproduzidas:

\begin{abstract}
As crianças expressam pensamentos e emoções com imaginação e criatividade: a arte orienta esta propensão, educando ao prazer do belo e ao sentir estético. A exploração dos materiais à disposição permite viver as primeiras experiências artísticas, que são capazes de provocar a criatividade e de contagiar outras aprendizagens. [...] O encontro das crianças com a arte é ocasião para olhar com olhos diferentes o mundo que as circunda. Os materiais explorados com os sentidos, as técnicas experimentadas e compartilhadas nos ateliês da escola, as observações dos lugares (praças, jardins, paisagens) e de obras (quadros, museus, arquiteturas) ajudarão a melhorar as capacidades perceptivas, cultivar o prazer da fruição da produção e da invenção e a aproximar à cultura e ao patrimônio artístico (Ministero della Pubblica Istruzione, 2012, p. 26).
\end{abstract}

Um passo necessário para confirmar esta importância é, porém interrogar-se sobre qual é o pensamento dos adultos, também neste caso subdividindo as reflexões em dois âmbitos. Em primeiro lugar interrogando-se sobre qual é o pensamento dos educadores ao organizar os ambientes educativos, não respondendo apenas às perguntas $O$ que farei com estas coisas? ou O que as crianças farão com estas coisas? Mas perguntando-se: Por que exatamente esta disposição, estas cores, esta organização? Qual é a ideia estética subjacente? Em segundo lugar, não limitando-se a agir com as crianças, propondo às vezes ações que se transformam em atividades repetitivas e limitadas, mas indagando-

1046 Educação \& Realidade, Porto Alegre, v. 40, n. 4, p. 1045-1060, out./dez. 2015. 
-se também neste caso seguindo uma perspectiva estética: Por que esta ações e não outras? O que implica esta escolha? Estas reflexões são o elemento determinante do próprio agir do educador, porque permitem descobrir quais são os pressupostos, as ideias pessoais sobre a arte e sobre as possibilidades de aplicação dentro das estruturas além da própria ideia de criança em relação a este âmbito. Um primeiro aprofundamento necessário deve ser feito, aqui, refletindo antes sobre qual significado podemos atribuir à palavra estética. Neste caso devemos nos referir à etimologia da palavra forjada por Alexander Gottlieb Baumgarten nos Prolegômenos: "1. A ESTÉTICA (ou seja, teoria das artes liberais, gnoseologia interior, arte do pensar belo, arte do análogo da razão) é a ciência do conhecimento sensitivo" (Baumgarten, 1992, p. 17). Entendemos, portanto, a ideia da estética como a de um contato experimental e de consciência através dos sentidos, não compreendida como disciplina referida exclusivamente a uma visão estereotipada de belo. Este ponto de vista pode ser ulteriormente aprofundado através das palavras do pedagogo Marco Dallari (2005, p. 18):

$$
\begin{aligned}
& \text { [...] esclareço imediatamente, para liberar o campo de } \\
& \text { equívocos desagradáveis e representações desviantes, } \\
& \text { como a experiência estética encontra a categoria da be- } \\
& \text { leza mas não se identifica com ela: Baumgarten cunhava } \\
& \text { o termo aesthetica da raiz aesth e do verbo aesthanomai } \\
& \text { que significa 'relacionar com alguma coisa através dos } \\
& \text { sentidos'. }
\end{aligned}
$$

É, portanto, nesta acepção que usaremos o termo estética, uma modalidade para entrar em contato com todos os sentidos, sem nos esquecermos do corpo na sua complexidade, uma maneira para conhecer e experimentar, colocando-se no interior do mundo artístico, uma categoria para observar em um modo diferente a realidade. Retomando as Indicazioni Nazionali italianas: "O encontro das crianças com a arte é oportunidade para olhar com olhos diferentes o mundo que as circunda" (Ministero dela Pubblica Instruzione, 2012, p. 26). Ora, passemos a observar também qual ideia pessoal temos de arte, acima de tudo como pessoas, antes mesmo de nos posicionarmos nas nossas definições profissionais. Neste caso milhares são as solicitações e o campo torna-se extremamente complexo, por isso é necessário, após termos posicionado a nossa hipótese sobre a arte, qualquer que ela seja, confrontar-nos com outras definições pronunciadas por críticos, artistas, personalidades do mundo cultural. Isto é feito sem a intenção de individualizar uma definição correta, na realidade impossível de se obter, mas para observar pontos de vista, colocados em uma pequena série, escolhendo qual reconhecemos como o mais próximo às nossas posições e qual podemos inserir em um contexto educativo. Se utilizarmos a palavra arte na acepção de Dino Formaggio podemos nos permitir, em um primeiro passo, graças a esta contribuição, de ter a mente livre de referências setoriais demais. Dino Formaggio, professor primário e também filósofo e

Educação \& Realidade, Porto Alegre, v. 40, n. 4, p. 1045-1060, out./dez. 2015.1047 
crítico de arte, nos acompanha em uma visão colocada historicamente, que pouca relação tem com a ideia de arte como manifestação do belo contraposto ao feio, percebida no sentido ascético e genérico. Mesmo considerando que haveria muito a ser discutido sobre esta visão, aqui se cita para um possível aprofundamento apenas dois ensaios de Umberto Eco intitulados História da Beleza (Eco, 2012) e História da Feiura (Eco, 2013), nos quais estes dois aspectos são indagados sem interpretá-los como valores absolutos, mas colocando-os em contextos históricos. Também a ideia de arte de Formaggio desliza nas épocas e na história ancorando-a ao pensamento e à ação humana. Eis a sua definição, que poderia, à primeira vista, parecer somente uma redundância: "A arte é tudo aquilo que os homens chamam de Arte" (Formaggio, 1973, p. 1), mas que nos permite também dentro das estruturas educativas, de proceder mais livremente, desvinculados de teorias complexas e pouco explícitas. Associemos esta definição a um pensamento mais operativo, como o de um artista, e neste caso escolhe-se privilegiar, entre tantos, Jackson Pollock, escolha efetuada justamente pela sua técnica revolucionária a nós proposta, aquela do dripping ou gotejamento, e o uso da tela disposta à terra como uma arena, sobre a qual o pintor se movia segundo um próprio ritmo interior de preenchimento da superfície pictórica: "A minha opinião é que novas necessidades implicam novas técnicas. E os artistas modernos encontraram novas maneiras e novos métodos para atingir seus objetivos [...] Cada época encontra sua técnica" (Pollock, 1999, p. 20). Um terceiro aspecto pode ser o que é oferecido pelas palavras de uma artista suíça contemporânea Pipilotti Rist:

Kunst, a palavra alemã para arte, tem relação com können, que significa 'ser capaz de': 'ser capaz': de aprender da vida (e as questões que esta coloca) com olhos bem abertos. A arte é um instrumento 'capaz de' propor experiências estéticas, encontros, confrontos, descobertas, interpretações, reflexões, atividades educativas, reelaborações e produções criativas, para todos (Tamanini, nota sobre o museu Mart, apud Zuccoli, 2014, p. 331).

Ou ainda, a quarta definição, extraída de um outro crítico, Nicolas Bourriaud, que colocou ênfase nos seus escritos sobre um outro elemento essencial da arte, o de ser relacional, uma relação que se instaura entre artistas e usufruidores em um jogo constante e mutável, e que aqui nos fala disto sob um ponto de vista de contínua transformação: "A atividade artística constitui um jogo cujas formas, modalidades e funções evoluem, segundo as épocas e os contextos sociais; não é uma essência imutável" (Bourriaud, 2010, p. 11).

Depois de termos ponderado sobre algumas possibilidades de definições de arte, à qual poderíamos certamente acrescentar outras, façamos agora um sucessivo passo, relativo a verificar qual tipo de concepção da arte tem quem entre nós trabalha com crianças, porque este aspecto tem uma fundamental reincidência. De fato, a ideia subjacente 
da arte, às vezes nem mesmo levada em consideração no seu aspecto mais global, em termos de conteúdos, de instrumentos além da modalidade de realização das propostas propriamente ditas. Se, com efeito, nos mantivermos na ideia de uma arte para ser admirada como uma forma concluída, a ser observada e para procurar compreendê-la, deduzindo uma série de significados, teremos um tipo de ação educativa ligada à compreensão e à cópia, no qual a nossa tarefa, como a das crianças, torna-se exclusivamente a de sermos espectadores e reprodutores imperfeitos do pensamento de outrem. Sobre este ponto é útil inserir as palavras de Bruno Munari, artista, designer e apaixonado por uma possibilidade de experimentação da arte pensada para as crianças, além de idealizador de muitas oficinas nos museus, um método para colocar-se em contato com as obras de arte. Ele nos desaconselha a nos relacionarmos com as obras de arte só para compreendê-las, para captá-las em uma tradução somente cognitiva, mas [sim] para nos aproximarmos delas procurando compreendê-las, para apreender propostas para interiorizá-las e torná-las próprias, enriquecendo o próprio olhar e a própria ação:

Entender ou compreender? O maior obstáculo à compreensão de uma obra de arte é o de querer entender. Com uma frequência demasiada, entender significa selecionar e dar definições que enquadram a obra em um esquema predefinido, compreender é, ao contrário, possuir com os próprios meios, entrando em contato estreito que deixará marcas indeléveis, fixadas na memória através vivência emotiva. Uma eficaz metodologia de abordagem das obras de arte, mediante atividade de pesquisa e aprofundamento teórico para conectar-se às experiências concretas de produção individual e coletiva em situação de oficinas (Munari, 1981a, p. 7).

A sua ideia era, não podendo trabalhar com os adultos, a este ponto confinados demais, na sua opinião, em um pensamento estético definido e enrijecido, de tentar com as crianças. Assim propunha ao museu de Brera, no longínquo ano de 1977, a criação de algumas oficinas:

E uma vez que é quase impossível modificar o pensamento de um adulto, nós deveremos cuidar das crianças. Os homens e as mulheres que formarão a nossa próxima sociedade futura, já estão aqui agora, têm 3 anos, $5,7 \ldots$ Se nós nos preocuparmos a mudar a sociedade para melhor, deveremos cuidar destes indivíduos que já estão aqui conosco. Proponho então de instalar, nos museus, algumas salas como oficinas: para crianças, onde elas possam ir dentro do museu para brincar com a arte visual, nestas oficinas poderiam encontrar materiais a serem usados e assistentes especializados em estimulação da criatividade visual (Munari, 1981a, p. 5).

Educação \& Realidade, Porto Alegre, v. 40, n. 4, p. 1045-1060, out./dez. 2015.1049 
Se, ao invés de entender e captar, em primeiro lugar considerarmos a arte e o contato com as obras como um diálogo e não um exclusivo ato de escutar, em que também nós, como usuários, temos uma parte necessária, podemos evocar as palavras de Gadamer (2006, p. 150-151), que sobre a relação dialógica que se constrói com qualquer tipo de obra literária, artística, musical põe sua atenção:

Nós somos por assim dizer atraídos pela obra em um diálogo. Assim a estrutura do diálogo não é por nada inoportuna se se deseja descrever adequadamente o aparente encontrar-se de frente que acontece entre uma obra de arte figurativa ou literária e seu intérprete. Este encontrar-se de frente é na verdade uma brincadeira de alternância e recíproca participação. [...] Na análise da estrutura do diálogo assistimos ao surgir de uma linguagem comum, em que os falantes se transformam e se encontram em algo comum.

A isto podemos acrescentar, estando no âmbito da arte figurativa, a ideia de arte relacional e participada, típica do contemporâneo, ao qual nos referíamos já antes (Bourriaud, 2010; 2011), no qual a obra de arte é captada na sua elaboração, não mais só como modelo, compreendendo-a, ao contrário, como busca e descoberta constante, que coloca em jogo tanto os autores quanto os espectadores. Um trabalho de pesquisa de resultados incertos, dos quais nas obras de arte, sobretudo aquelas do passado podemos colher a conclusão, o produto perfeito de uma longa ação de experimentação, reflexão, dada como concluída; enquanto no caso da arte contemporânea muito frequentemente podemos nos inserir ainda no seu formar-se participando (Bordini, 2007; Sgarbi, 2012; Vergine, 1999; Vettese, 2005; Vettese, 2012). É esta a hipótese dos happening ou das instalações (Bordini, 2007; Vettese, 2010; 2012), na qual se compartilha o seu desenvolver-se, entrando como espectador partícipe em seu ser em desenvolvimento de ajudando as próprias obras a concluírem-se e a obter determinados resultados. Nas estruturas educativas e nas escolas frequentemente nos encontramos frente a uma proposta ao invés de percursos definidos e concluídos, que na maioria das vezes se referem a projetos obsoletos. Eis o que dizia sempre Bruno Munari (1984, p. 11-12):

Há dois modos de configurar um programa de ensino falamos neste caso de arte. Há um modo estático e um modo dinâmico. Há um modo no qual o indivíduo é forçado a adaptar-se a um esquema fixo, quase sempre superado ou, no melhor dos casos, em vias de superamento na realidade prática de cada dia. E um outro modo que pouco a pouco se vai formando, modificado continuamente pelos mesmos indivíduos e pelos seus problemas sempre mais atuais. No caso do ensino estático, com programas fechados e imutáveis, cria-se frequentemente um sentido de desconforto, [...] o estudante, entendida a inutilidade

1050 Educação \& Realidade, Porto Alegre, v. 40, n. 4, p. 1045-1060, out./dez. 2015. 
de um protesto qualquer para adaptar o ensino aos seus verdadeiros interesses, segue sem entusiasmo. No caso do ensino dinâmico, os docentes estudam um programa de base, o mais avançado 'possível e portanto continuamente modificável segundo os interesses que emergem do próprio ensino. Somente no fim do percurso saber-se-á qual forma terá e como terá se desenvolvido.

Obviamente as palavras de Munari se referem em primeira instância a jovens e estudantes maiores do que aqueles que podemos encontrar nas nossas estruturas, e aqui se fala de fato do próprio ensino, o que não concerne às nossas estruturas educativas, mas a hipótese de fundo não foge a esta lógica. De uma ideia de arte, experimentada e vivenciada em primeiro lugar como educadores na própria formação de estudantes, ponderada com o contato com o mundo atual e as experiências culturais vividas, passa-se a uma hipótese de arte a ser ensina$d a$, aquele saber erudito transformado em saber ensinado de que fala Chevallard (1985) fornecendo-nos também a definição de transposição didática, que pode ser aplicável a qualquer conteúdo cultural, do qual descende por exemplo a proposta concreta nas estruturas. Com ensinar aqui não se entende uma aula expositiva ou catedrática, na qual um adulto fala e as crianças escutam, ao contrário, se orienta à ideia ligada à significativa predisposição de ambientes, de materiais e de instrumentos, além da sua oferta às crianças (Nigris, 2003), sempre à luz das perguntas: O que proponho? A quem proponho? Como o faço? Com qual modalidade e quais tempos? e acima de tudo Por que o faço? Todas essas reflexões iniciais sobre a arte e suas concepções pensadas em qualidade de adultos, sobre que coisa derive destes termos de pensamento educativo e sucessivas propostas concretas com as crianças, são um necessário pré-requisito para efetuar escolhas conscientes e apropriadas às modalidades de conhecimento do mundo que as próprias crianças experimentam continuamente.

De fato, se continuarmos nesta direção, associando-a às próprias peculiaridades da ação artística (Dewey, 1995; Munari, 1981a; Munari, 1981b; Munari, 1984; Munari, 2009) devemos redescobrir uma ação educativa que seja baseada na descoberta e na experimentação constante, sem um único resultado já definido a priori. Retomando as reflexões de Joy Paul Guilford sobre o pensamento divergente, podemos observar como se trata de uma ação que se move na direção de:

\begin{abstract}
[...] um modo de pensamento produtivo, típico da criatividade, que propende ao novo eu. Em comparação ao pensamento convergente que propende ao conhecido e à justa solução, o pensamento divergente recorre onde um problema deve ainda ser definido ou descoberto e onde não existe alguma sugestão para resolvê-lo (Cassese; Granato, 2011, p. 100).
\end{abstract}

Se ouvirmos contemporaneamente as palavras de Bruno $\mathrm{Mu}$ nari, podemos redescobrir a importância da fantasia, entendida não

Educação \& Realidade, Porto Alegre, v. 40, n. 4, p. 1045-1060, out./dez. 2015.1051 
Formar-se com Arte entre Museu e Pré-escola

como algo de abstrato ou destinado exclusivamente a poucos eleitos, os artistas, mas como uma possibilidade de cada um de nós ligada à necessidade de colocar as coisas em relação, e mais relações temos à disposição, mais esta possibilidade aumenta em profundidade e extensão: “[...] o produto da fantasia, como o da criatividade e da invenção, nasce de relações que o pensamento faz com aquilo que conhece [...]. A fantasia, portanto, será mais ou menos frutífera se o indivíduo tiver mais ou menos possibilidades de fazer relações” (Munari, 1977, p. 15). Cada organização de espaços, cada ação artística proposta e conduzida com as crianças movimenta proposições, que condicionam energicamente o nosso agir dentro das estruturas, às vezes até mesmo não consciente. Tendo em conta estas afirmações, é necessário, segundo a autora, que sobre estes aspectos, quando se desenvolvem percursos de formação com os educadores, que não se fale em modo teórico fora de contextos significativos, mas se possam experimentar concretamente no campo de atuação, sobretudo naquele cultural, abrindo as portas das estruturas educativas, saindo destas e indo aos museus, além de outros espaços, como bibliotecas, ou a contato com os vários patrimônios (naturais e humanos). Em particular, neste artigo, propõem-se algumas experiências realizadas nos museus de arte, especificamente arte contemporânea, ainda que não exclusivamente e no museu do design, para efetuar ali percurso de conhecimento e de formação, retornando sucessivamente com olhares novos para dentro do próprio lugar de trabalho. Um ponto mais geral, após ter realizado muitos momentos de formação nas pré-escolas, ainda que com assuntos diversos, é como estas sejam majoritariamente significativas se dão lugar primeiramente a projeto de pesquisa-ação ou de pesquisa-formação (Mantovani, 1998), que na especificidade do campo de intervenção artística se baseiam nas linhas da Art Based Research (McNiff, 1998), na qual é a própria modalidade artística a se tornar um elemento transformador. Um primeiro dado é que, para que as formações consigam alimentar um circuito virtuoso entre prática e teoria, é necessário que as crianças estejam profundamente presentes desde o início, graças a uma ideia de projeto construído em conjunto, educadores/as e pedagogos/as, observado e documentado no tempo. No caso de formações entendidas em senso artístico, dentro das creches e das pré-escolas, considera-se fundamental, porém, abrir-se diretamente ao contato com a esfera da arte, a nós, mais contemporânea. É no encontro direto com a arte que pode ocorrer algo de significativo. Não somente no falar sobre ela ou no ouvir algumas explicações, mas no escandalizar-se ou no surpreender-se, confrontando-se com algumas obras ou experimentando alguns percursos artísticos. Uma ação a ser realizada em ambientes diversos, caracterizados por propor-se específica ordem cultural, contaminando o mundo educativo com aquele artístico. A atenção ao contemporâneo, que é a arte da nossa época, resulta fundamental em particular se se evidenciam alguns elementos, que caracterizam esta modalidade artística, e que podem se coligados ao próprio fazer educativo além da exploração típica

1052 Educação \& Realidade, Porto Alegre, v. 40, n. 4, p. 1045-1060, out./dez. 2015. 
das crianças. Ei-los aqui elencados, sabendo que ao resumi-los corre-se o risco de esquecer algumas especificidades além de criar excessivas generalizações: pensamento de projeto (Munari, 1984) com escolhas, reflexões, tentativas, modificações e realizações que procedem lado a lado; experimentações constantes no próprio fazer projetável e artístico; uso de materiais inovadores e inusitados; criação de técnicas novas, restabelecimento de antigas; atenção ao corpo e às suas relações espaciais e constitucionais; contaminações e sobreposições de várias linguagens; busca de novas modalidades expressivas e comunicativas; produções expostas, visíveis, confrontáveis; arte que se faz relacionável (Bourriaud, 2010; Bourriaud, 2011) na qual o produtor/artista é um elemento que tem necessidade da presença do utente para existirem artista e público em relação permutável. Observando a experimentação e o uso do material, é interessante referir-se próprio a alguns textos ligados à arte contemporânea. Aquele, por exemplo, de Marina Pugliese diretora do Museo del Novecento em Milão, intitulado Tecnica Mista (Pugliese, 2006), é este, de fato, um dos termos que encontramos geralmente nas plaquinhas ao lado dos quadros, esculturas, instalações. Isso para nos dizer que não existem mais somente materiais nobres, específicos da arte, e sobre isto abriremos parênteses daqui a poucas linhas, mas que cada coisa pertencente também ao cotidiano, ao descartado, tem direito de entrar na experimentação artística.

\begin{abstract}
O uso na escultura de materiais anormais facilmente deperíveis (como papelão, lata e fio de ferro) mina um postulado fundamental da escultura tradicional: a duração. Entre a escultura oitocentista em bronze e mármore, monumental e celebrativa, e as composições feitas com materiais variados, frágeis e desprovidas de pedestais, o hiato é enorme (Pugliese, 2006, p. 15).
\end{abstract}

Em um outro texto (Bordini, 2007), chega-se até mesmo a elencar as possibilidades de articulação de um mesmo material, os polímeros sintéticos referindo-se à sua exploração estética: “[...] opaco, transparente, duro, macio; apresentam-se em estado líquido ou espumoso, em película, em folhas transparentes, podem ser também tecidos, etc..." (Bordini, 2007, p. 59). E isto nos recorda a complexidade de materiais propostos às crianças nas experiências de arte na escola onde o trabalho sensorial se torna elemento fundamental no proceder educativo (Guerra, 2013; Munari, 2008; Restelli, 2002). Um referimento deve ser feito, em particular, aos resíduos e material reciclável, que a este ponto invadiram as ribaltas das exposições, modificando a nossa própria percepção e solicitando, após o seu retiro do mundo dos objetos úteis e usufruíveis, um olhar diverso e um diferente uso (Vergine, 2006; Guerra, 2013). Também estes tornaram-se patrimônio dos serviços educativos, que entre carências de fundo e intenções criativas, recolhem com as duas mãos os resíduos de materiais ou elementos reciclados ou recicláveis. Se nos detivermos ainda em particular na arte contemporânea,

Educação \& Realidade, Porto Alegre, v. 40, n. 4, p. 1045-1060, out./dez. 2015.1053 
mas analisando-a também no seu complexo a partir de mil e novecentos, podemos notar como a exigência de propor uma modalidade de comunicação que abrange de forma irrevocável o público seja hoje um de seus elementos mais caracterizantes (Vettese, 2010; 2012), graças a performances e instalações em que é necessário implicar o espectador (Bourriaud, 2010; Bourriaud, 2011).

Um sucessivo passo é aquele de colocar as potencialidades da arte, depois de tê-las referido ao mundo artístico, dentro do pensamento pedagógico. Neste caso as referências podem ser algumas figuras que se ocuparam disso como John Dewey, Herbert Read e Vea Vecchi da escola de Reggio Emilia. De John Dewey destacamos neste contributo, sobretudo o aspecto experimental, o título de seu texto Arte come Esperienza (a edição original é de 1934), nos permite de compreender a escolha por ele feita de não ver a arte como algo de separado da vida quotidiana de todos os homens, criando polêmica com quantos ao contrário tentam "[...] colocar a arte em um pedestal, fazer da arte algo de esotérico, de separado dos valores inerentes a todas as experiências das coisas na sua plena integridade: e também algo de separado das necessidades quotidianas do homem" (Dewey, 1995, p. 445). O próprio Herbert Read (1943) nos fala de uma educação através da arte e, portanto, uma arte que permeia todos os aspectos da educação, sem relegar-se exclusivamente em um único aspecto disciplinar, mas trabalhando em um primeiro lugar sobre a própria maneira da construção do conhecimento se se utilizam cânones estéticos e produtivos típicos do ambiente artístico. Por último, entre as muitas experiências que estão sendo realizadas atualmente em vários lugares, também as propostas educativas de Reggio Emilia (Reggio Children), em que a execução artística se torna um aspecto fundamental que permeia as ações que são realizadas com as crianças, para isso é necessário pontualizar o valor da presença nestes lugares do ateliê (Vecchi, 2002; Vecchi; Giudici, 2004). A própria Vea Vecchi, criadora junto com Loris Malaguzzi, desta nova atenção de respeito na presença da arte nas estruturas educativas, assim responde em uma entrevista, referindo-se ao papel do ateliê:

Como uma possibilidade de ter mais pontos de vista e onde o belo, a escolha estética, não são considerados opcionais, mas uma necessidade do pensar e do viver. Como contributo à ruptura de velhos esquemas pedagógicos, transformando em ativas as mãos, a cabeça e as emoções das crianças e dos professores. Como possibilidade de tornar visíveis algumas das capacidades das crianças. [...] $\mathrm{O}$ ateliê nunca foi considerado um lugar separado e especializado do resto da pré-escola: desde súbito a linguagem visual participou e se entrelaçou com todos os campos do saber (Edwards; Gandini; Forman, 1995, p. 137-138).

Após ter observado a arte do ponto de vista dos artistas e dos críticos, como potencialidade transformadora, os pedagogos e os educadores que se ocuparam disso, vamos ver como o próprio museu pode se 
tornar um elemento essencial da comunicação artística, um ator principal na formação mesma dos educadores transformando-se em uma parte ativa, junto com os formadores e os pedagogos, ao propor aos educadores um contato não intermediado com as obras de arte. Deve-se fazer, súbito, uma premissa de como atualmente os museus, em particular aqueles científicos e de arte contemporânea, adotamos uma nova potencialidade que se distancia da comunicação ascética e destacada que no tempo os tinha contradistintos. De museu templo, assim como foi definido no passado, chegou-se a um museu fórum ou um museu lugar de encontro no qual é mais fácil pôr-se em relação às coisas expostas e onde quem trabalha se interroga não somente sobre os objetos expostos (Zuccoli, 2010), mas também sobre o público e sobre quais ocasiões prazerosas e formativas que respondam às suas necessidades reais, possam ser colocadas na prática. Nos vários museus as seções didáticas e os departamentos educativos, de acordo com a denominação que cada país escolheu, oferecem ao público mais variado uma série de propostas. Estas propostas alcançam a especificidade das coleções, mas se modificam em uma atualização constante procurando interceptar as exigências dos visitantes e de respeitar as transformações das formas culturais e do saber em constante evolução (Hooper-Greenhill, 2005).

Neste artigo, ao final destas primeiras reflexões teóricas ligadas aos possíveis significados do uso da arte, indagada ao nível pessoal e filosófico, conduzindo-as em seguida ao contexto das estruturas onde se manifesta com a atenção aos materiais, ao ambiente, às modalidade experimentais de pesquisa, deseja-se propor algumas experiências de formação efetuadas nas estruturas educativas e nos museus. Desde sempre a formação, unida à reflexão individual e coletiva sobre o trabalho realizado e sobre a documentação do mesmo é um dos pilares do percurso de crescimento e de mudança de um educador, mas segundo o parecer de quem escreve, deve-se repensar na moldura com que algumas destas atualizações são propostas. Em particular, referindo-se a um âmbito artístico, não é coerente com o assunto de base se considerarmos como elemento fundamental da arte uma experimentação e um contato com as obras do passado e do contemporâneo, realizar os cursos exclusivamente dentro das escolas ou das estruturas educativas sem mergulhar em novos espaços e confrontar-se com curadores e responsáveis dos serviços educativos nos museus. A relação entre escola, serviços educativos e museu é, hoje, parte fundamental de muitas instituições museológicas. Pode ser, porém, oportuno ampliam ainda mais esta relação realizando experiências, não somente destinadas às crianças, mas também a educadores e professores. As cinco experiências que aqui se deseja resumir foram desempenhadas no último ano letivo (2013-2014) com grupos de educadores e professores das creches, pré-escolas e escolas primárias (mais de duzentas) que são a coligação com o Corso di Laurea in Scienze della Formazione Primaria da Universidade de Milão Bicocca. Estas formações previram experiências repetidas no interior dos seguintes contextos museológicos: Hangar Bicocca, Trien-

Educação \& Realidade, Porto Alegre, v. 40, n. 4, p. 1045-1060, out./dez. 2015.1055 
Formar-se com Arte entre Museu e Pré-escola

nale Design Museum, e MUBA, Museo dei Bambini, neste último caso se tratava de um percurso realizado com a professora Monica Guerra especificamente sobre o uso de materiais inusitados (Guerra, 2013; Zuccoli, 2010) sempre em Milão. Em todas essas formações, a partir de uma reflexão pessoal sobre os conceitos de arte e sobre quantos outros autores (antigos e outros mais contemporâneos para nós) tinham salientado sobre o mesmo argumento, além de uma observação a respeito do que, no interior das estruturas educativas vinha sendo realizado, através de documentação e vídeos, encaminhou-se em um segundo momento nos vários museus citados para se desenvolver novas hipóteses. Imediatamente a proposta oferecida não era a de aproximar-se às obras de arte contemporânea o de design com a ideia de o que realizar com as crianças, mas de colocar-se em contato como adultos, percorrendo as instalações, observando os espaços, brincando com alguns materiais propostos, refletindo em um segundo momento juntos sobre quais contributos tinham sido apreciados, o que tinha incomodado, o que tinha convencido, comunicando ao grupo as próprias impressões.

Deve-se evidenciar como os museus escolhidos não fossem, na maioria, nem conhecidos, nem frequentados, e se tratassem de museus com a presença de exposições temporárias. Em cada museu os responsáveis pelos serviços educativos foram os interlocutores principais do encontro, que não tinha sido pensado como uma clássica visita guiada, mas como uma experiência coletiva, cuja presença dos especialistas à disposição resultou fundamental para tornar explícitas as modalidades das escolhas do curador, as hipóteses comunicativas do museu, as específicas instâncias de cada artista. Muito material impresso e vídeos estavam à disposição nestes museus, para enriquecer o contato com as obras. A possibilidade de vivenciar pessoalmente, distantes ainda de uma lógica educativa, tinha levado a refletir sobre suas próprias especificidades da arte contemporânea que, como já vimos precedentemente, arrisca entre muitas potencialidades na escolha dos materiais na busca constante de novas modalidades expressivas, no contato com o público. Estas experiências realizadas não se desenvolveram em um único museu, mas de forma consciente pelo menos em dois destes elencados, diferentes por tipologia. Em primeiro lugar no Hangar Bicocca que é concebido como um centro de arte contemporânea, onde as exposições são construídas pelos curadores com um contato articulado e profundo com os vários artistas interpelados, e o material à disposição do público é extremamente rico e variado (de escritos, livros, artigos, comunicados, vídeos, festivais de filmes escolhidos pelos próprios artistas e projetados em noites específicas). Em segundo lugar no museu Triennale Design Museum cujo design, uso dos objetos e projeto tornam-se elementos fundamentais das várias exposições, propondo cada ano uma diferente interpretação do design italiano. Em terceiro lugar no $M U B A$, um museu para crianças que, na exposição Caixas - Scatole (realizada com a supervisão de Monica Guerra), tinha em seu interior também a presença de algumas obras de arte propositadamente realizadas para

1056 Educação \& Realidade, Porto Alegre, v. 40, n. 4, p. 1045-1060, out./dez. 2015. 
esta montagem e consentia de vivenciar percursos sensoriais, que envolviam todo o corpo. Sempre no $M U B A$, em um outro espaço podia-se trabalhar com materiais de resíduo industrial e material reciclável (Guerra, 2013; Zuccoli, 2010). Depois destas experiências realizadas nos museus, pensando também em criar uma familiaridade com estes novos lugares, de modo que pudessem se tornar elementos estáveis no patrimônio cultural de educadores e professores, o pensamento compartilhado voltou aos lugares em que se desenvolvia a ação educativa com as crianças. Em uma reflexão coletiva obteve-se quanto daquilo que tinha sido vivenciado nos museus podia ter uma direta implicação, em termos de organização de espaços, materiais e instrumentos a serem propostos, experiências a serem oferecidas e compartilhadas com as crianças, dentro da própria profissão. Este pensamento tinha servido também para repensar de modo mais genérico na própria proposta no âmbito da educação à arte. De todas essas experiências, recolhendo as avaliações sobre a ação de formação proposta, a totalidade dos participantes apreciou, em particular, a possibilidade de sair das estruturas educativas, de dirigir-se a outros lugares e de encontrar os responsáveis dos mesmos (neste caso dos museus) realizando um discurso além da especificidade profissional deles. Isto serviu, segundo o parecer dos educadores, para retornar em um segundo momento a obter a valência que estes novos encontros com as obras de arte e os museus tinham oferecido a eles para enriquecer a proposta educativa. Esta mesma formação levou durante este novo ano escolar (2014-2015) a projetar novos percursos dentro das escolas e das estruturas educativas e a ir não somente a estes museus, mas em outros para poder solicitar experiências significativas a serem inseridas no próprio percurso educativo. $\mathrm{O}$ valor da vivência da descoberta foi um elemento fundamental, como a própria modalidade das oficinas utilizada nas estruturas e nos museus, uma modalidade para ser redescoberta também com as crianças considerando que:

[...] consente de ter experiência direta com as coisas, de olhar com os próprios olhos, tocar com as próprias mãos, de satisfazer a própria curiosidade, de procurar razões [...] A criança se baseia naquilo que acontece diretamente sob seus olhos [...] Através da experiência do laboratório a criança pode aproveitar a ocasião, enquanto realiza a própria atividade direta, de apropriar-se de instrumentos para fazer buscas: à medida que executa a própria atividade, ficará sempre menos contente da solução imediata e mais simples e interessar-se-á, consequentemente, sempre mais e pouco a pouco mais detalhado, à solução dos problemas, ao desejo de encontrar razões escondidas, à exigência de elaborar métodos pessoais e/ou compartilhados por outros (Borghi, 2003, p. 49).

Concluindo esta colaboração deseja-se salientar quatro aspectos fundamentais: o primeiro é o que se refere a uma educação à arte que

Educação \& Realidade, Porto Alegre, v. 40, n. 4, p. 1045-1060, out./dez. 2015.1057 
redescubra a própria potencialidade formativa seja para as crianças, seja para os educadores atingindo o campo cultural em que estamos imersos e que, assim fazendo, recupere aquela distância que frequentemente as estruturas educativas e as escolas vivem em relação às propostas culturais que as circundam; o segundo ponto localiza-se na vontade de valorizar o potencial intuitivo, imaginativo e experimental de educadores e crianças, projetando modalidades e lugares diferentes para as formações e os percursos de reflexões sobre o próprio trabalho, além de dar mais espaço a experiências estéticas e intuitivas, que alcancem o campo da arte: como terceiro o pedido de abrir as portas das estruturas educativas e das escolas incentivando a contaminação com outros lugares de cultura, museus, bibliotecas, lugares de patrimônio natural, para que crianças e educadores possam ser um trâmite além das ações naqueles lugares também de solicitações na projetação de atividades participadas (Moscati; Nigris; Tramma, 2008); por último uma reflexão sobre a formação de educadores e professores em si, pensando em como é importante renová-la apostando em elementos que são parte de uma visão cultural e social. Trata-se, como bem escreve Pietro Sacchetto (2000, p. 9-10), de:

Questões que se referem, além do âmbito específico da educação artística, à experiência de conhecimento passado e presente, a relação com os saberes que se decide de compartilhar com os rapazes, a disponibilidade de confrontar-se com a contemporaneidade. [...] Por confrontar-se com a contemporaneidade não pretendo dizer certamente a corrida pela atualidade, mas sim a prática da interrogação constante e ciente do que acontece ao nosso redor - também muito perto de nós e interpela a nossa segurança, traz à tona contradições de explicações das ações humanas dadas por adquiridas e compartilhadas, põe em discussão lógicas lineares demais na interpretação de fenômenos históricos, culturais, artísticos, científicos. Acredito que resulte evidente como pela sua natureza este processo se refira às duas dimensões da biografia do/a docente: a mais pessoal, enquanto sujeito colocado conscientemente no tempo em que vive e transpassado portanto pelos fenômenos que em vários níveis o/a caracterizam.

Esta ideia foi colocada neste ponto pensando que uma formação profissional, para incidir realmente sobre as ações sucessivas que vão se cumprir nas estruturas educativas, deve oferecer ocasiões de confronto com o mundo cultural contemporâneo em que estamos submersos e deve nos fazer refletir, a partir de experiências pessoais que coloquem em jogo também as nossas posições, sobre novos percursos de descoberta e de conhecimento pessoais e profissionais.

Recebido em 18 de novembro de 2014 Aprovado em 12 de maio de 2015

Revisão Técnica da Tradução: Ligia Maria Leão de Aquino

1058 Educação \& Realidade, Porto Alegre, v. 40, n. 4, p. 1045-1060, out./dez. 2015. 


\section{Referências}

BAUMGARTEN, Alexander Gottlieb. Estetica. Milano: Vita e Pensiero, 1992.

BORDINI, Silvia (Org.). Arte Contemporanea e Tecniche: materiali, procedimenti, sperimentazioni. Roma: Carocci, 2007.

BORGHI, Battista Q. Crescere con i Laboratori: manuale di didattica dei laboratori nella scuola dell'infanzia. Bergamo: Edizioni Junior, 2003.

BOURRIAUD, Nicolas. Estetica Relazionale. Milano: Postmedia Srl, 2010.

BOURRIAUD, Nicolas. Postproduction: come l'arte riprogramma il mondo. Milano: Postmedia Srl, 2011.

CASSESE, Francesco Peluso; GRANATO Sacha. Introduzione alla Psicopedagogia del Gioco. Roma: Edizioni Universitarie Romane, 2011.

CHEVALLARD, Yves. La Transposition Didactique: du savoir savant au savoir enseigné. Grenoble: La Pensée Sauvage, 1985.

DALLARI, Marco. L'Arte per i Bambini. In: FRANCUCCI, Cristina; VASSALLI, Paola (Org.). Educare all'Arte. Milano: Mondadori Electa, 2005. P. 17-25.

DEWEY, John. Arte Come Esperienza e Altri Scritti. Firenze: La Nuova Italia, 1995.

ECO, Umberto (Org.). Storia della Bellezza. Milano Bompiani, 2012.

ECO, Umberto (Org.). Storia della bruttezza. Milano:Bompiani, 2013.

EDWARDS, Carolyn; GANDINI, Lella; FORMAN, George. I Cento Linguaggi dei Bambini: l'approccio di Reggio Emilia all'educazione dell'infanzia. Azzano San Paolo: Edizioni Junior, 1995.

FORMAGGIO, Dino. L'Arte. Milano: ISEDI, 1973.

GADAMER, Hans-Georg. L'Attualità del Bello: studi di estetica ermeneutica. Genova: Marietti, 2006.

GUERRA, Monica. Materiales no Convencionales en la Escuela: experiências didácticas y potencialidad formative. RELAdEI, Santiago de Compostela, v. 2, n. 1, p. 105-120, mar. 2013.

HOOPER-GREENHILL, Eilean. I Musei e la Formazione del Sapere: le radicistoriche, le pratiche del presente. Milano: Il Saggiatore, 2005.

MANTOVANI, Susanna (Org.). I Metodi Qualitativi. Milano: Bruno Mondadori, 1998. MCNIFF, Shaun. Art-Based Research. London: Jessica Kingsley Publisher, 1998. MINISTERO DELLA PUBBLICA ISTRUZIONE. Indicazioni Nazionali per il Curricolo della Scuola dell'Infanzia e del Primo Ciclo d'Istruzione. Firenze: Le Monnier, 2012

MOSCATI, Roberto; NIGRIS, Elisabetta; TRAMMA, Sergio. Dentro e Fuori la Scuola. Milano: Bruno Mondadori, 2008.

MUNARI, Bruno. Fantasia. Roma-Bari: Editori Laterza, 1977.

MUNARI, Bruno. Il Laboratorio per Bambini a Brera. Bologna: Zanichelli, 1981a.

MUNARI, Bruno. Il Laboratorio per Bambini a Faenza. Bologna: Zanichelli, 1981b.

MUNARI, Bruno. Design e Comunicazione Visiva. Roma-Bari: Editori Laterza, 1984.

MUNARI, Bruno. I Laboratori Tattili. Mantova: Edizioni Corraini, 2008.

Educação \& Realidade, Porto Alegre, v. 40, n. 4, p. 1045-1060, out./dez. 2015.1059 
MUNARI, Bruno. Da Cosa Nasce Cosa. Roma-Bari: Editori Laterza, 2009.

NIGRIS, Elisabetta. Didattica Generale. Milano: Guerini, 2003.

POLLOCK, Jackson. My painting, 1947-48. In: KARMEL, Pepe (Org.). Jackson Pollock: interviews, articles, reviews. New York: The Museum of Modern Art, 1999.

PUGLIESE, Marina. Tecnica Mista: materiali e procedimenti nell'arte del XX secolo. Milano: Bruno Mondadori, 2006.

READ, Herbert. Education Through Art. London: Faber \& Faber, 1943.

RESTELLI, Beba. Giocare con Tatto: per un'educazione sensoriale secondo il metodo Bruno Munari. Milano: Franco Angeli, 2002.

SACCHETTO, Pietro. Incontro All'arte: appunti di un viaggio con i bambini di 3 , 4 e 5 anni. Azzano San Paolo: Edizioni Junior, 2000.

SGARBI, Vittorio. L'Arte è Contemporanea Ovvero come l'Arte di Vedere L'Arte. Milano: Bompiani/RCS, 2012.

VECCHI, Vea (Org.). Sipario Anello delle Trasformazioni. Reggio Emilia: Reggio Children, 2002.

VECCHI, Vea; GIUDICI, Claudia (Org.). Bambini, Arte, Artisti: i linguaggi espressivi dei bambini, il linguaggio artistico di Alberto Burri. Reggio Emilia: Reggio Children, 2004.

VERGINE, Lea. L'Arte in Trincea: lessico delle tendenze artistiche 1960-1990. Milano: Skira, 1999.

VERGINE, Lea. Quando i Rifiuti Diventano Arte: trash, rubbish, mongo. Milano: Skira, 2006

VETTESE, Angela. Ma Questo è un Quadro? Il valore dell'arte contemporanea. Roma: Carocci, 2005.

VETTESE, Angela. Si Fa con Tutto: Il linguaggio dell'arte contemporanea. Roma-Bari: Gius. Laterza \& Figli, 2010.

VETTESE, Angela. L'Arte Contemporanea: tra mercato e nuovi linguaggi. Bologna: Il Mulino, 2012.

ZUCCOLI, Franca. Dalle Tasche dei Bambini: gli oggetti, le storie e la didattica. Parma: Edizioni Junior-Spaggiari, 2010.

ZUCCOLI, Franca. Didattica tra Museo e Scuola: antiche e nuove forme del sapere. Parma: Edizioni Junior-Spaggiari, 2014.

Franca Zuccoli é professora da Universitá Degli Studi Milano Bicocca, do Departamento Scienze Umane per La Formazione "Ricardo Massa”, em Milão, na Itália. É professora pesquisadora de Arte-educação e de Educação Geral. Supervisora da Educação de departamentos de ensino de museus de arte contemporânea. Temas: formação docente em arte, pré-escola, arte, museu.

E-mail: franca.zuccoli@unimib.it 